Type of the Paper (Article)

\title{
Effect of rainfall variability on the maize varieties grown in a changing climate: a case of smallholder farming in Hwedza, Zimbabwe
}

\author{
Mugiyo, $\mathrm{H}^{1^{*}}$. Mhizha, $\mathrm{T}^{2}$. Mabhaudhi $\mathrm{T}^{3}$ \\ 1.Environmental Sciences, University of KwaZulu-Natal, P. Bag X01, Scottsville, Pietermaritzburg 3209, \\ South Africa \\ 2.Department of Physics, University of Zimbabwe and School of Agricultural, Earth and 3. Environmental \\ Sciences, University of KwaZulu-Natal, P. Bag X01, Scottsville, Pietermaritzburg 3209, South Africa \\ ${ }^{1}$ Corresponding author: mugiyoh@gmail.com, tmhizha@gmail.com², mabhaudhi@ukzn.ac.za ${ }^{3}$
}

Abstract: Rain-fed maize production has significantly declined in Zimbabwe especially in semi-arid and arid areas causing food insecurity. Erratic rainfall received associated with mid-season dry spells largely contribute to low and variable maize yields. This study involved a survey of current farmers' cropping practices, analyses of climatic data (daily rainfall and daily minimum and maximum temperature) of Hwedza station and simulation of maize yield response to climate change using DSSAT CERES crop growth simulation model. The climatic and maize yield data was analysed using mean correlation and regression analyses to establish relationships between rainfall characteristics and maize yield in the study area. Survey results showed that maize was the staple food grown by $100 \%$ of the farming households while $8.7 \%$ also grew sorghum. The survey concludes that $56.2 \%$ of the farmers grew short season varieties, $40.2 \%$ medium season varieties and $3.6 \%$ long season varieties. The result of the correlation analysis of climatic data and maize yield showed that number of rain days had strong positive relationship $(r=0.7)$ with maize yield. Non-significant yield differences $(p>0.05)$ between maize cultivar and planting date criteria were obtained. Highest yields were obtained under the combination of medium season maize cultivar and the DEPTH criterion in all simulations. The range of simulated district average yields of $0.4 \mathrm{t} / \mathrm{ha}$ to $1.8 \mathrm{t} / \mathrm{ha}$ formed the basis for the development of an operational decision support tool (cropping calendar).

\section{KEYWORDS}

Crop Modelling, DSSAT, Climate variability, Survey, Maize, Crop guidelines/Cropping calendar

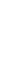
(1)

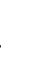
6 7 8 9 0 1 


\subsection{Introduction}

In Zimbabwe, agriculture is one of the key sectors of the economy (Matutu, 2014), with an estimated $80 \%$ of the population directly dependent on agriculture. Over $65 \%$ of farmers practice rain-fed farming for their livelihood (Johnson and Chivandi, 2010; Mapfumo, 2013).Agriculture sector contributes $20.1 \%$ to the gross domestic product (GDP)(Crop, 2013). It is apparent that an agricultural production crisis is developing in Zimbabwe due to a steep decline in agricultural production(Mapfumo, 2013). This conclusion is based on declining income derived from agriculture as compared with non-agricultural sectors and the fact that the growth rate of agriculture has deteriorated relative to the population growth rate. In addition the status of the country as, "the food basket of the Sothern Development Community (SADC)" is gradually dwindling largely due to several factors and amongst them are climate related factors. Zimbabwe's climate is changing with the rate of change seemingly faster than what is normally expected(Asseng, 2015; Geerts and Raes, 2012; Hertel and Lantz C. Baldos, 2016; Sithole and Murewi, 2009). As a result, the climate of Zimbabwe is now characterized by many extreme events such as severe storms, floods and droughts, strong winds, hail, frost and heat waves (Sithole and Murewi, 2009; Zinyengere et al., 2014).

Low agriculture production in Zimbabwe may be attributed to several factors such as market forces that are disincentives, lack of irrigation facilities, inability of the farmers to access inputs in time, conservative attitudes towards extension services, field operations, timing of planting, and superimposed on these is the lack of use of adequate climate information (Conway et al., 2008). Climate change and variability have become topical issues in recent time because of their largely detrimental impacts on natural and human systems(Mugalavai et al., 2008; Phillips et al., 1998). The most frequently cited activities or operations likely to be affected by climate change are agriculture, forestry, hydrology and fisheries especially in semi-arid regions (Laura, 2017).Within the agriculture sector, an extreme event like drought is arguably the most important climatic challenge and has major impacts on rain-fed cereal yields (Chimonyo et al., 2016; Kosgei, 2009; Mabhaudhi et al., 2018; Mendelsohn, 2008).

Use of agro-climatic information can improve rain-fed production but there is a general lack of readily available useable information accessible to farmers to achieve this (Keating et al., 2003; Mhizha et al., 2014). In agriculture, decision support tools for making choices such as crop variety selection, planting dates and timing of fertilizer application can contribute to increased yields under rain-fed conditions (Geerts and Raes, 2012; Hsiao et al., 2009; Vanuytrecht et al., 2014). However these decision support guidelines for rain-fed farming systems are not available to resource-poor farming communities such as subsistence farmers in Zimbabwe(Mhizha et al., 2014; Mupangwa et al., 2011; Raes et al., 2004; Zinyengere et al., 2014). Optimum management practices, such as planting criteria and cultivar selection can be accessed through validated models such as DSSAT for making seasonal or within-season decisions (Pickering, 1996; Vanuytrecht et al., 2014). One tool which can fill this gap is a crop calendar. A crop calendar is a tool that provides timely climate related information about crops and varieties to promote local crop production. It contains information on planting dates, sowing and harvesting periods of locally adapted crops in specific agro-ecological zones (Mendelsohn et al., 2006). 
Previous attempts to study effects of rainfall on crop yield in Zimbabwe (Alumira and Rusike, 2014; Crop et al., 2012a; Mhizha, 2010; Mhizha et al., 2014; Mupangwa et al., 2011; Raes et al., 2004; Zinyengere et al., 2011) were based on some rainfall characteristics such as dates of onset and end of rainy season, and temperature. Though these studies were comprehensive, farmers' practices and important rainfall characteristics, like rain days that are also vital to crops were not considered. It is against this backdrop that this study focuses on examining the length of growing seasons and matching them with crop growth cycles in Hwedza district of Zimbabwe. Planting windows, best planting combination and variety selection were developed into a maize crop calendar that will guide farmers on planting dates, dry spell probability during critical stages of the crop growth cycle and rainfall cessation. In addition, current common farmers' practices were investigated through a sampling survey. Historical climate was characterized from observed daily temperature and rainfall data and a crop growth simulation model DSSAT (Decision Support System for Agro-technology Transfer) version 4.5 was used to explore implications of observed changes in daily rainfall records on district maize average yield.

\subsection{Materials and Methods}

\subsection{The study area}

The study was carried out in Hwedza district of Zimbabwe, (Figure 1). The geographic position for Hwedza climate station is: latitude $-18^{\circ}$, longitude $31^{\circ}$ and altitude $1425 \mathrm{~m}$. The average total annual rainfall for Hwedza is $807 \mathrm{~mm}$. The rainy season starts in November and tails off in April. Ther is wide spatial and temporal variation in rainfall. The mean annual temperature ranges from $18-19{ }^{\circ} \mathrm{C}$ at about $1400 \mathrm{~m}$ above sea level. Maximum temperatures are low in the winter months (June-July) and highest in the month of October (Crop et al., 2012b).

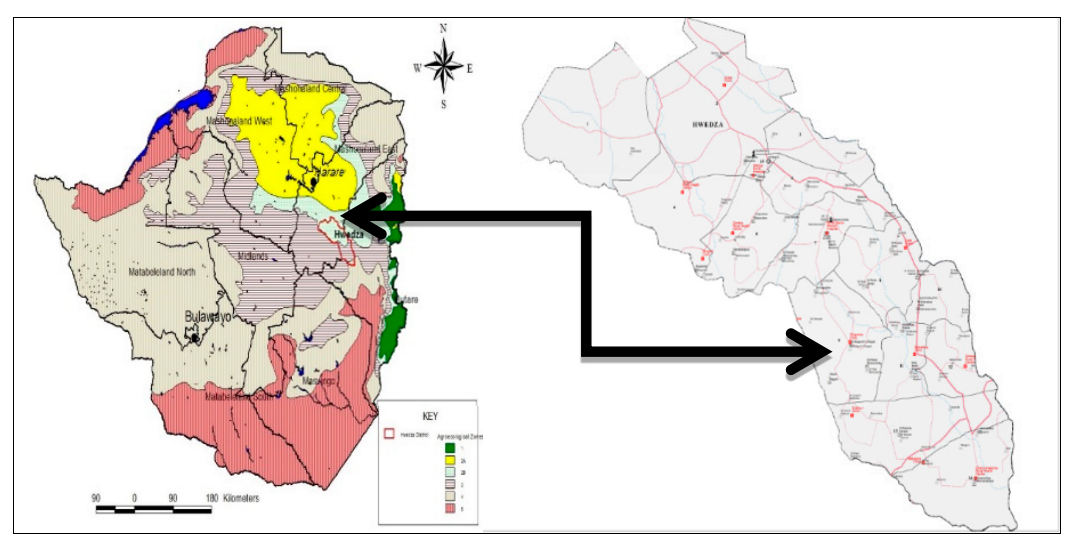

Figure 1: Map of Zimbabwe showing agro ecological zones and Hwedza district

Hwedza livelihoods are mainly crop production based, with mixed crop- livestock systems hinged on maize production, as well as groundnut, soya bean and cowpea. 


\subsection{Importance of socio-economic surveys in agriculture}

In research farmers experience and practice are the backbone of research questions. One of collecting data is through surveys. Survey research involves the collection of information from a sample of individuals through their responses to questions. Survey research owes its continuing popularity to its versatility, efficiency, and generalizability (Quantity and Marsh, 2017). Surveys are efficient in that many variables can be measured without substantially increasing the time or cost(Bank and Change, 2018; World and Annual, 2008).For a survey to succeed, it must minimize the risk of two types of error: poor measurement of cases that are surveyed (errors of observation) and omission of cases that should be surveyed (errors of non-observation) (Division and Banda, 2003; Peytchev et al., 2011) . Potential problems that can lead to errors of observation stem from the way agro-meteorological questions are written, the characteristics of the farmers who answer the questions, the way questions are presented in questionnaires, and the interviewers used to ask the questions.

\subsubsection{Sampling design}

A stratified two stage random sampling design was used for the survey. The sample size was based on central limit theorem and sample size calculation formula was based on the assumption of normal Approximation, (Davis et al., 2016; Division and Banda, 2003).

\subsection{Agroclimatic characterization}

\subsubsection{Meteorological data}

One meteorological station was selected for this study; the station was selected based on availability of meteorological data. Forty nine years of daily rainfall data of Hwedza station for the period 1963 to 2012 was collected from Meteorological Service Department (MSD). The choice of this length of period is in line with the convention of using 30 years' weather data in characterizing the climate of an area, as adopted by the World meteorological Organization (Scafetta and B. J. West, 2009).

\subsubsection{Rainfall}

The following definitions were used during weather characterizations.

- agricultural rain (wet) day: when an area receives $4.95 \mathrm{~mm}$ or more of rainfall

- rain day: when an area receives $2.95 \mathrm{~mm}$ or more of rainfall

- dry day: any day that accumulates less than $2.95 \mathrm{~mm}$ of rain

- water logging rains: At least $100 \mathrm{~mm}$ of rain within five consecutive days

The season was considered to have started if an area receives effective planting rains. In the study, INSTAT "Climatic Events" menu options was used to define events of interest (start of season, dry spell, water balance)(Gallagher and Stern, 2015). Then sowing dates were based on the following definitions commonly agreed upon with the farmers,

1. AREX criterion, first date from 1 st October when an area receives more than $25 \mathrm{~mm}$ in 7 days with the condition that there is no 10 day dry spell or longer within the next 20 days.

2. MET criterion, first date from 1st October when an area receives at least $40 \mathrm{~mm}$ in 15 days, with the condition that there is no 10 day dry spell or longer within the next 20 days.

3. Depth criterion, first date from 1st October when an area receives at least $40 \mathrm{~mm}$ in 4 days (Mugalavai et al., 2008). 
160

161

162

163

164

165

166

167

168

169

170

171

172

173

174

175

\subsection{Climate impact scenario assessment with DSSAT and Simulation procedure}

In this study the DSSAT model was calibrated and validated using the district average observed data.

\subsubsection{Weather data}

The three main weather parameters required for use by the DSSAT model are: daily rainfall $(\mathrm{mm})$, daily minimum temperatures $\left(\mathrm{T}^{\circ} \mathrm{C}\right)$ maximum temperature $\left(\mathrm{T}^{\circ} \mathrm{C}\right)$ and daily solar radiation $\left(\mathrm{MJ} / \mathrm{m}^{-2}\right)$.

\subsubsection{Soil characteristics}

The soil texture characteristics at Hwedza were considered to be in Group G5- felsic igneous and metamorphic rocks, moderately deep coarse loam (Mtambanengwe and Mapfumo, 2005). The field capacity and wilting point for textural classes of Zimbabwe are found at $-10 \mathrm{kPa}$ and $-1500 \mathrm{kPa}$ suction pressures respectively (Journal, 1983; Mtambanengwe and Mapfumo, 2005) (Table 1).

Table 1. Physical characteristics of the soils used in crop simulations (Nyamangara et al., 2000)

\begin{tabular}{|c|c|c|c|c|}
\hline Depth (cm) & $0-15$ & $25-40$ & $50-65$ & $90-105$ \\
\hline DM \% & 99.7 & 99.2 & 98.8 & 98.2 \\
\hline Texture & $\mathrm{mLS}$ & mSal & $\mathrm{cSaCl}$ & $\mathrm{cSaC}$ \\
\hline Gravel \% & 1 & 3 & 6 & 9 \\
\hline Course sand \% & 17 & 17 & 20 & 20 \\
\hline MediumSand \% & 32 & 26 & 22 & 16 \\
\hline Fine Sand \% & 38 & 31 & 24 & 20 \\
\hline Silt \% & 8 & 8 & 5 & 5 \\
\hline Clay \% & 4 & 18 & 29 & 39 \\
\hline $\mathrm{pH}\left(\mathrm{CaCl}_{2}\right)$ & 4.0 & 4.2 & 5.0 & 5.2 \\
\hline Carbonates & 0 & 0 & 0 & 0 \\
\hline EX Ca (me \%) & 0.7 & 1.1 & 1.8 & 1.5 \\
\hline EX Mg (me \%) & 0.1 & 0.2 & 0.6 & 0.7 \\
\hline EX Na (me \%) & 0.02 & 0.02 & 0.02 & 0.02 \\
\hline EX K (me \%) & 0.24 & 0.12 & 0.24 & 0.14 \\
\hline TEB (me \% ) & 0.9 & 1.5 & 2.7 & 2.3 \\
\hline CEC (me \%) & 0.9 & 2.0 & 3.1 & 4.1 \\
\hline Base Sat \% & 100 & 75 & 87 & 57 \\
\hline $\mathrm{E} / \mathrm{C}$ & 21.3 & 11.4 & 10.6 & 10.6 \\
\hline $\mathrm{S} / \mathrm{C}$ & 21.3 & 8.5 & 9.2 & 6.0 \\
\hline ESP & 2.1 & 1.0 & 0.7 & 0.5 \\
\hline EKP & 25.6 & 6.1 & 8.0 & 3.5 \\
\hline Org Carbon \% & 0.29 & 0.19 & 0.14 & 0.17 \\
\hline
\end{tabular}


177

178

179

180

181

182

183

184

185

186

187

188

189

190

191

192

193

194

195

196

197

198

199

200

201

202

203

204

205

206

207

208

209

210

211

212

213

214

\subsubsection{Management and Experiment Data}

Planting dates The planting dates used for the study were based on the optimal plantings commonly used in Zimbabwe. In this study, method applied are the Depth criterion, MET criterion and AREX criterion dates (Raes et al., 2004).

\section{Fertilizer management}

Two levels of fertilizer application were used: a 'optimal' level and a lower level more representative of resource poor farming communities in Hwedza.

Model calibration and validation

The DSSAT model was calibrated by continuously adjusting the maize genotypic input parameters so as to mimic observed average district grain yield. The model was calibrated using the observed average district grain yield data collected from 1999 to 2008.

The CERES groups of models require a set of parameters describing the crop environment interactions, termed genetic coefficients. To use the CERES maize models in Zimbabwe, the genetic coefficients of the widely grown varieties were obtained from CIMMYT, (CAO et al., 2012; Jones et al., 2003) (Table 2).

Table 2. Genetic coefficients of Zimbabwe maize varieties

\begin{tabular}{lllllll}
\hline Maize cultivar & P1 & P2 & P5 & G2 & G3 & PHINT \\
\hline Short Cultivar & 110 & 0.30 & 680 & 820 & 6.6 & 38.9 \\
Medium & 200 & 0.30 & 800 & 700 & 8.5 & 38.9 \\
Long Cultivar & 320 & 0.52 & 940 & 620 & 6.0 & 38.9 \\
\hline
\end{tabular}

P1: length of the juvenile period (degree days above $8^{\circ} \mathrm{C}$

P2: Factor to account for delay in development when day length is less than the optimum

P5: Time in degree days from silking to maturity

G2: Maximum kernels per plant

G3: Kernel filling rate ( $m g /$ day) during grain filling under optimum conditions

PHINT: Phyloochron interval (time in degree days between successive leaf tip appearance)

\subsection{Model validation}

Validation of the model was done by use of the root mean square error (RMSE). The RMSE is a measure of the difference between the simulated predicted outcomes.

3.0 Results and Discussion

\subsection{Survey Results}

\subsubsection{Gender}

Out of 438 sampled farming household, 34.9\% were females farming households while $65.1 \%$ were males. In Hwedza there fewer females who are household heads.

\subsubsection{Cropping information}

The descriptive statistics from SPSS, showed that 100\% of farming households in Hwedza grew maize because it is a strategic and staple grain food in Zimbabwe. Sorghum is a drought tolerant cereal crop but is grown by only $8.7 \%$ of farming household in Hwedza district, especially in communal area and small scale sectors.

\subsubsection{Start of season from the survey}

In Hwedza, the start of the season varies depending on farmers location micro climates . Out of 438 farmers interviewed (Table 3) the start of season is very variable. There is no consistent of start of 
season. The inconsistent of start of season might attributed to climate variability in Zimbabwe (Zinyengere et al., 2015) .

Table 3. Start of season in Hwedza district

\begin{tabular}{llllllll}
\hline Month & October & & November & & December \\
& & & & & & \\
\hline Dekad & 1 & 2 & 3 & 1 & 2 & 3 & 1 \\
Respondent as $\%$ & $2.1 \%$ & $22.1 \%$ & $18.7 \%$ & $7.5 \%$ & $18.0 \%$ & $31.4 \%$ & $0.2 \%$ \\
\hline
\end{tabular}

\subsubsection{Analyzed start season from historical data using INSTAT}

Three criteria for determining the start of season were analyzed using INSTAT. According to the AREX criterion, the season often starts on the $2^{\text {nd }}$ dekad of November (11 November), while it starts on $2^{\text {nd }}$ dekad of November (16 November) based on the MET criterion with the Depth criterion giving a common start of season on the $3^{\text {rd }}$ of November (day 148) of the Julian calendar starting from 1 July. The $t$-tests of correlations (at the $5 \%$ level of significance) (figure2) exposed that there was no significant trend in the planting dates computed by any of the three criteria over the past 49 years (Fiwa et al., 2014). From the analysis of Depth criterion with less risk of crop failure after the start of there is evidence that the climate variability (Sithole and Murewi, 2009) is significantly affecting the onset of the cropping season (figure 2). The variability of onset dates with time on a station further proves a well-known point that rainfall pattern and distribution from one station cannot be used as representative enough to give operational guidelines of the whole district. There are different microclimates in Hwedza district which was proved by the survey results.

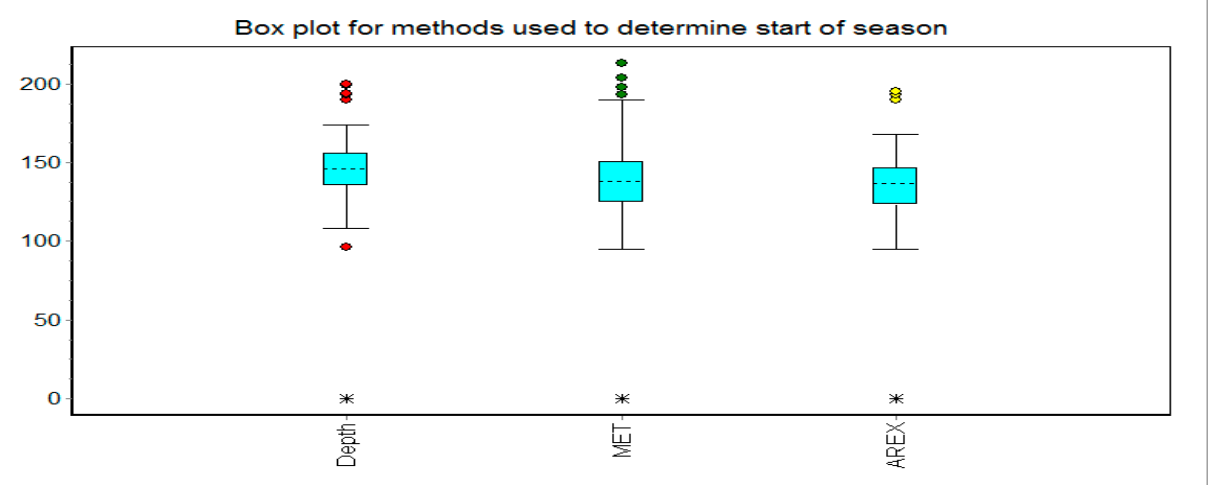

Figure 2. Vertical boxplot showing criteria used to determine start of season

\subsubsection{Occurrence of dry spells}

The probability and occurrence interannual fluctuations in precipitation-dry spells were reported in Hwedza (Table 4). Dry spells cause water stress in maize. Water is one of the main yield reducing factors in maize production. Availability of adequate moisture at rootzone is essential for maize development. Scarcity of water (drought stress) at critical stages (anthesis and grain filling) of maize cause yield loss(Basir et al., 2018). Potential yield can be reduced by 10-50\% if dry spells occurs at 816 leaf stage of maize phenology. Water stress during this period will reduce ear size and potential 
yield(A Ahmed et al., 2018). With high chances of having dry spells greater 14 days (17\% chance) (Table 4 ) in January and 14 days (15\% in February) maize potential yield is reduced.

Table 4 . Risk of 14 day, 21 day and 28 days dry spells in a season at Hwedza station

\begin{tabular}{llll}
\hline & \multicolumn{2}{l}{ Percent chance of occurrence of dry spells of duration not less than: } \\
\hline Month & 14 days & 21 days & 28 days \\
November & $40 \%$ & $16 \%$ & $8 \%$ \\
December & $10 \%$ & $0 \%$ & $0 \%$ \\
January & $17 \%$ & $0 \%$ & $0 \%$ \\
February & $15 \%$ & $7.7 \%$ & $7.6 \%$ \\
March & $26 \%$ & $10.5 \%$ & $0 \%$ \\
\hline
\end{tabular}

Results from survey and analysis of historical data (Table 4) rainfed maize anthesis period in Hwedza takes place between January and February. The critical maize growth stages (silking and grain filling) often coincide with mid-season dry-spells. Silking stage is the most sensitive stage for water stress. Water stress during silking coupled with high temperatures can result in 100 percent loss (Fiwa, Resources and Raes, 2014; Zinyengere et al., 2015; A Ahmed et al., 2018; Basir et al., 2018). This explains the importance of growing varieties which match with length of growing period. Dry weather that starts early and covers several growth periods will have a compounding effect with severe reductions in maize and sorghum yields. False starts of the rainy season cause replanting and increase cost of production of rain fed crops in Zimbabwe, therefore starts of season need to be monitored to reduce risk of crop failure (Mupangwa et al., 2011).

\subsubsection{Agricultural seasonal rainfall characteristics and maize phenology}

There is a marked decrease in total amount rainfall received in January and February for 49 years analyzed (Figure 3a). A marked decrease in total rainfall received in January and February signify characteristics of climate change. There is a gradual decrease in total rain received in month of January from selected 10 year period (1992, 2002 and 2012) which is a sign of climate change in Hwedza (Sithole and Murewi, 2009). In rainfed maize production January and February months are critical because the dates usually correspond with critical stages of cereal crop growth.

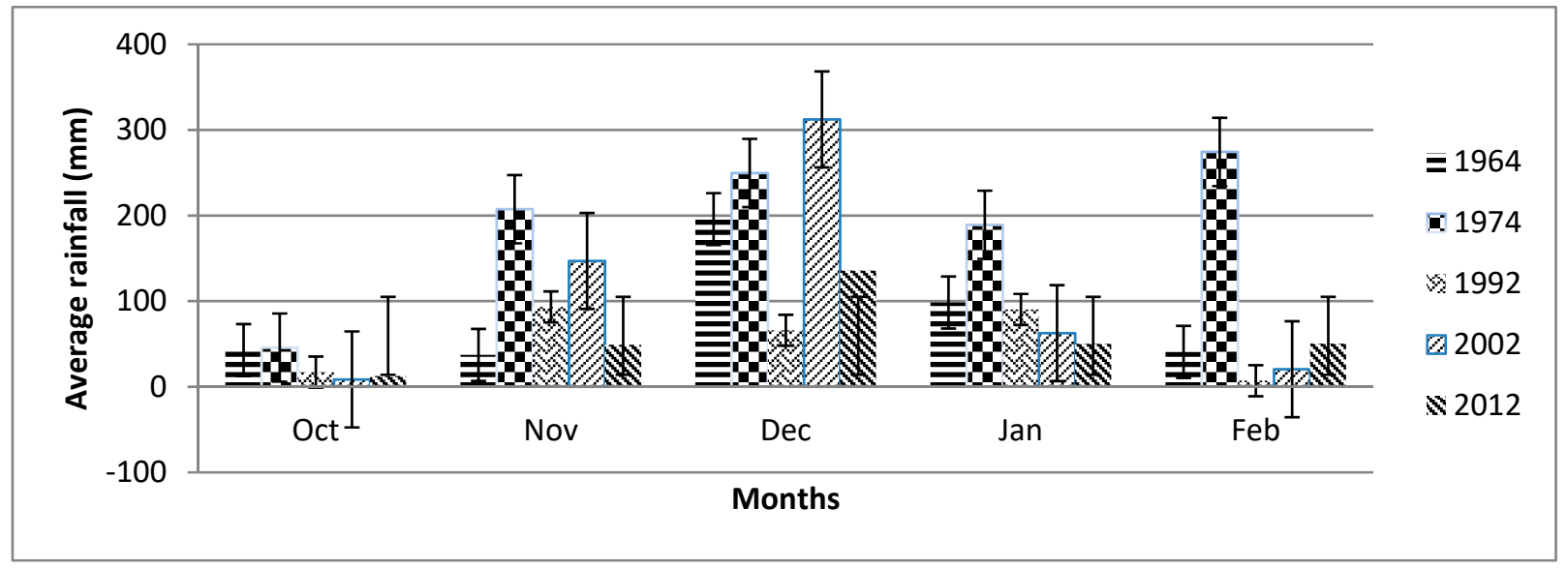

Figure 3. Hwedza monthly rainfall changes. Error bars show mean deviation 
270

271

272

273

274

275

276

277

278

279

280

281

282

283

284

285

The average seasonal rainfall showed a significant increase (Figure 3). A significant increase of total seasonal precipitation is not important in rainfed maize production. What matters in crop phenology development is the rainfall distribution (Geerts and Raes, 2012). Analyzed climatic data of Hwedza station there is a marked decrease in number of rain days in a season (Figure 4). Two definitions were used to define the agricultural rain day: (a) any day when an area receives $4.95 \mathrm{~mm}$ or more of rainfall, (b) any day when an area receives $2.95 \mathrm{~mm}$ or more of rainfall.

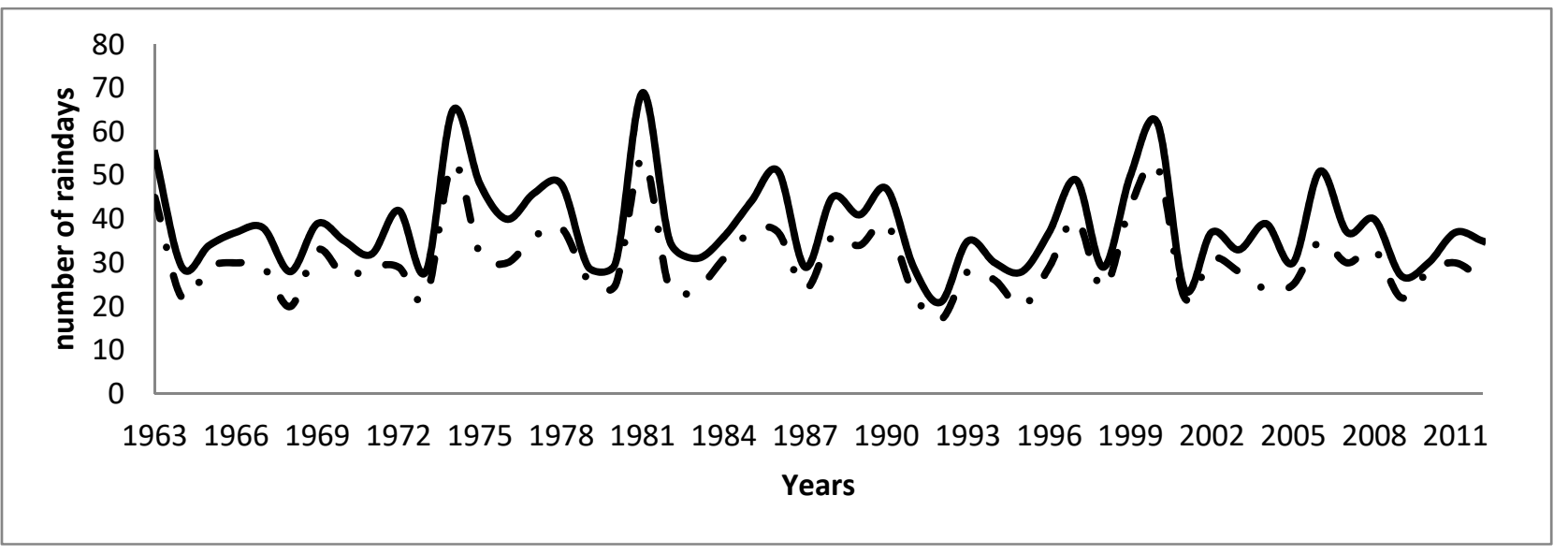

Figure 4. Number of rain days in a season (dashed line = rain days $>2.95$; continuous line = rain days $>$ $4.95 \mathrm{~mm}$ )

\subsection{Modelling results}

\subsubsection{Grain yield calibration}

Comparison of simulated grain yield cultivar and observed data was done only for period of 20002008 due to lack of long term maize grain district average and temperature data during simulation (Table 5).

Table 5. Average district observed yields and simulated grain yields

\begin{tabular}{lllll}
\hline \multirow{2}{*}{ Year } & District & \multicolumn{3}{l}{ Simulated Yields $\mathbf{( T / H a )}$} \\
\cline { 3 - 5 } & Observed Yields & Short Varieties & Medium Varieties & Long Varieties \\
& $\mathbf{( T / H a )}$ & & & \\
$\mathbf{2 0 0 0}$ & 0.5 & 1.5 & 1.3 & 0.4 \\
$\mathbf{2 0 0 1}$ & 1.4 & 0.9 & 1.6 & 0.6 \\
$\mathbf{2 0 0 2}$ & 0.6 & 1.0 & 1.1 & 0.4 \\
$\mathbf{2 0 0 3}$ & 1.0 & 0.5 & 0.6 & 0.4 \\
$\mathbf{2 0 0 4}$ & 1.4 & 0.5 & 0.5 & 0.6 \\
$\mathbf{2 0 0 5}$ & 0.6 & 0.5 & 0.4 & 0.4 \\
$\mathbf{2 0 0 7}$ & 1.1 & 0.6 & 1.0 & 0.5 \\
$\mathbf{2 0 0 8}$ & 0.9 & 0.7 & 0.9 & 0.6 \\
\hline
\end{tabular}
happening in the farming system (Geerts and Raes, 2012; Zinyengere et al., 2014;Chisanga, Phiri and Chinene, 2017; Ndawayo et al., 2017).Calibration of district grain yield simulation was done by assessing the goodness of fit of simulated against grain yield and also two sample t-test at $95 \%$ 
292 the RMSE was greater than $30 \%$ which was considered to be a poor simulation result(Chisanga et al., 293 2017; Geerts and Raes, 2012; Zinyengere et al., 2015). This was due to the missing yields which were 294 experienced in 1991/1992 in (Table 6). The missing yields were attributed to the drought which was 295 experienced in the 1991/1992 season (Unganai and Kogan, 1993; Kuri et al., 2014; Mutowo et al., 2014; 296 Asseng, 2015).

297 Table 6. Simulated average yields in (Tonnes-T) from 1981-2008

\begin{tabular}{|c|c|c|c|c|c|c|c|c|c|}
\hline \multirow{2}{*}{$\frac{\text { Cultivar }}{\text { Planting }}$} & \multicolumn{3}{|c|}{ Short Varieties } & \multicolumn{3}{|c|}{ Medium Varieties } & \multicolumn{3}{|c|}{ Long Varieties } \\
\hline & Depth & MET & AREX & Depth & MET & AREX & Depth & MET & AREX \\
\hline \multicolumn{10}{|l|}{ Criteria } \\
\hline Year & Yield(T) & Yield(T) & Yield(T) & Yield(T) & Yield(T) & Yield(T) & Yield(T) & Yield(T) & Yield(T) \\
\hline 1981 & 1.3 & 1.4 & 0.7 & 2.4 & 2.8 & 2.8 & 0.7 & 0.7 & 0.7 \\
\hline 1982 & 1.2 & 1.2 & 2 & 2 & 2 & 2 & 0.8 & 0.8 & 0.8 \\
\hline 1983 & 1.1 & 1.0 & 1 & 2.6 & 2.4 & 2.4 & 0.6 & 0.7 & 0.7 \\
\hline 1984 & 1.4 & 1.4 & 1.4 & 2.4 & 2.4 & 2.4 & 0.6 & 0.6 & 0.6 \\
\hline 1985 & 1.6 & 1.4 & 1.4 & 2.3 & 2.5 & 2.3 & 0.7 & 0.7 & 0.7 \\
\hline 1986 & 1.1 & 1.5 & 1.5 & 1.7 & 2.4 & 2.4 & 0.6 & 0.6 & 0.6 \\
\hline 1988 & 1.2 & 1.4 & 1.4 & 2.2 & 1.9 & 1.9 & 0.7 & 0.6 & 0.6 \\
\hline 1989 & 1.3 & 1.3 & 1.3 & 2.4 & 2.4 & 2.4 & 0.6 & 0.6 & 0.6 \\
\hline 1990 & 1.2 & 1.2 & 1.2 & 2.6 & 2.6 & 2.6 & 0.5 & 0.5 & 0.5 \\
\hline 1991 & 1.5 & 1.1 & 1.1 & 2.2 & 1.5 & 1.5 & 0.4 & 0.4 & 0.4 \\
\hline 1992 & 0 & 0 & 0 & 0 & 0 & 0 & 0 & 0 & 0 \\
\hline 1993 & 1.3 & 1.5 & 1.5 & 2.9 & 2 & 2 & 0.5 & 0.5 & 0.5 \\
\hline 1994 & 1.1 & 1.3 & 1.3 & 2.9 & 2.7 & 2.7 & 0.7 & 0.7 & 0.7 \\
\hline 1995 & 0.8 & 1 & 1 & 1.8 & 2.8 & 2.8 & 0.6 & 0.5 & 0.5 \\
\hline 1996 & 1.1 & 1.4 & 1.4 & 2.1 & 2.3 & 2.3 & 1 & 0.9 & 0.9 \\
\hline 1997 & 0.9 & 0.9 & 0.9 & 2 & 2 & 2 & 0.5 & 0.5 & 0.5 \\
\hline 1998 & 1.5 & 1.5 & 1.5 & 3 & 3 & 3 & 0.5 & 0.5 & 0.5 \\
\hline 1999 & 1.2 & 1.3 & 1.3 & 2.4 & 2.6 & 2.6 & 0.8 & 0.8 & 0.8 \\
\hline 2000 & 1.5 & 1.5 & 1.5 & 1.3 & 1.3 & 1.3 & 0.4 & 0.4 & 0.4 \\
\hline 2001 & 0.9 & 0.9 & 0.9 & 2.1 & 2.1 & 0.6 & 0.6 & 0.6 & 0.6 \\
\hline 2002 & 1.1 & 0.9 & 0.9 & 1.1 & 1.1 & 1.1 & 0.4 & 0.4 & 0.4 \\
\hline 2003 & 0.6 & 0.4 & 0.4 & 0.5 & 0.6 & 0.6 & 0.3 & 0.4 & 0.4 \\
\hline 2004 & 0.5 & 0.5 & 0.4 & 0.5 & 0.5 & 0.6 & 0.6 & 0.5 & 0.6 \\
\hline 2005 & 0.6 & 0.4 & 0.4 & 0.4 & 0.4 & 0.4 & 0.4 & 0.4 & 0.4 \\
\hline 2007 & 0.6 & 0.6 & 0.5 & 1.1 & 0.9 & 0.9 & 0.5 & 0.5 & 0.5 \\
\hline 2008 & 0.6 & 0.7 & 0.7 & 0.9 & 1 & 0.9 & 0.6 & 0.6 & 0.6 \\
\hline
\end{tabular}

The long season cultivar which requires greater than 150 days to mature gave lowest yields $(0.3 \mathrm{t} / \mathrm{ha})$ (Table 6) when planted late because the average length of growing season is 139 days therefore the cultivar failed to reach physiological maturity. Maize is a C4 plant; its optimum photosynthesis rate is at optimum at $\left(28-35^{\circ} \mathrm{C}\right)$, which is around January to February. Around this period the probability 
303

304

305

306

307

308

309

310

311

312

313

314

315

316

317

318

319

320

321

322

323

324

325

326

327

328

329

330

331

332

333

334

335

336

of experiencing dry spells greater than 14 days is very high. Water stress at anthesis period and grain filling reduce yield drastically.

\subsection{2: Validation of simulated results}

By using GenStat, the separation of the mean was carried out to find which varieties are most suitable in Hwedza and were compared with results from observed maize district average yields. The simulated results for medium season and short season varieties showed no significant difference from the observed maize district average yield, $\mathrm{P}=0.6$ and $\mathrm{P}=0.16$, respectively while significantly difference were obtained between simulated results for long season varieties and district average, $\mathrm{P}$ $=0.004$ (Fiwa et al., 2014; Zinyengere et al., 2015). The results from the survey farmers who grew long term varieties were $3.6 \%$, medium term varieties $40.2 \%$ and short-term varieties $56.2 \%$. In research, finding farmers experiences and practices of farmers are important in crop modelling and in development of cropping guidelines. Farmers perceptions make calibration and validation of model easy. In science of modelling garbage in garbage out scenarios are common(K. L. MACKERRON, 1999; Mukhtar, 2012). During fine tuning a model it's important to compare simulated results and data from baseline surveys.

\subsubsection{Evaluating planting criteria and maize cultivar}

STATA version 15.0 was used to evaluate the effects of planting criteria and maize cultivar (Figure 5). The variance ratio for planting criteria to maize varieties was not significant as illustrated by standard mean errors bars (Figure 5). The combination of AREX criterion and maize varieties produced highest yields followed by MET criterion and lastly, the depth criterion. The results show less significant differences in yield obtained from simulation with different combination of planting criteria. The combination of depth criterion and medium season cultivar is recommended because depth criterion has less risk of crop failure (Raes et al., 2004).

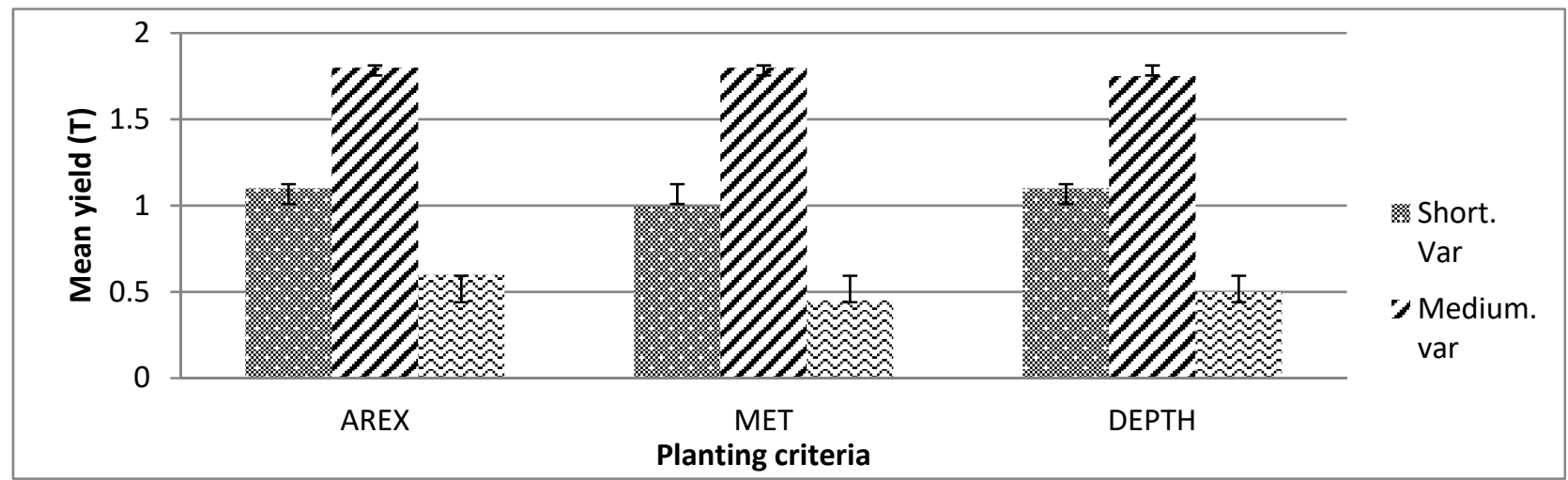

Figure 5. Combination of planting Criteria and cultivar (AREX, MET, DEPTH criterion) effects on yield

By planting late, farmers avoid the potential false starts which may occur early in the season. This ensures that crops do not suffer moisture stress in the initial and crucial stages of development(Chivenge et al., 2015). The medium and short varieties obtain better yields when planted late and early. The maize yield of short and medium varieties was insignificantly affected by time of planting (Figure 5). 


\subsection{4: Cultivar optimization for maize crop calendar}

Testing of null hypothesis that mean of medium, short and long-term varieties were equal to mean of observed yields (Table 7). Medium and short varieties ( $\mathrm{P}=0.6333$ and $\mathrm{P}=0.169)$ respectively (Table 7) there's no difference between the means and conclude that a significant difference does exist.

Table 7. Varieties optimization

\begin{tabular}{l|lllll}
\hline Sample & Mean $(\mathrm{T} / \mathrm{Ha})$ & Variance & $\begin{array}{l}\text { Standard } \\
\text { deviation }\end{array}$ & $\begin{array}{l}\text { Standard error } \\
\text { of mean }\end{array}$ \\
\hline Baseline yields & 1.022 & 0.168 & 0.410 & 0.137 & 0.633 \\
Medium. Variety & 0.925 & 0.169 & 0.412 & 0.146 & 0.169 \\
Short. Variety & 0.750 & 0.130 & 0.361 & 0.128 & 0.004 \\
Long. Variety & 0.479 & 0.009 & 0.099 & 0.035 & \\
\hline
\end{tabular}

The results (Table 7) are consistent with observation by(Mhizha et al., 2014; Phillips et al., 2006) that medium-term varieties are dominant in agro-ecological region IIb and III in Zimbabwe, while in drier zones the more drought-tolerant crops, pearl millet (Pennisetum glaucum. L) and sorghum (sorghum bicolor.L) are recommended. Some farmers are risk takers they grow long varieties $(\mathrm{P}$ value $<0.05)$ (Table 7) where there's difference between the means and conclude that a significant difference exist. Climate variability confuse farmers to extent of choosing maize varieties which don't match with crop varieties water requirements. In some LaNina years farmers benefits from well distributed rains which favors better yields from long maize variety.

\subsubsection{Relationship between total seasonal rainfall, simulated yield and observed yields}

The simulated results showed that DSSAT is sensitive to moisture stress, it failed to simulate 1992 yields because of the drought experienced in that season (Figure 6), shows that in years where total seasonal rainfall was greater than $700 \mathrm{~mm}$ simulated and observed yields were greater than 1 tonne. Not all years with totals seasonal rainfall greater than $700 \mathrm{~mm}$ had good yields, this proves that rainfall distribution (rain days) is more important than seasonal totals. In a season, if severe midseason dry-spells greater than 14 days occur at anthesis and grain filling stages, final maize yields are affected. Maize requires about $600 \mathrm{~mm}$ of rainfall of even distribution to reach physiological maturity. In case of low seasonal total rainfall (less than $600 \mathrm{~mm}$ ) and few rain days (erratic rainfall distribution) growing of small grains is highly recommended. In Hwedza only $7.8 \%$ of farmers grew sorghum (or other small grains) which implies that farmers are advised to grow both maize and sorghum to reduce the negative impact of climate variability on yields. 


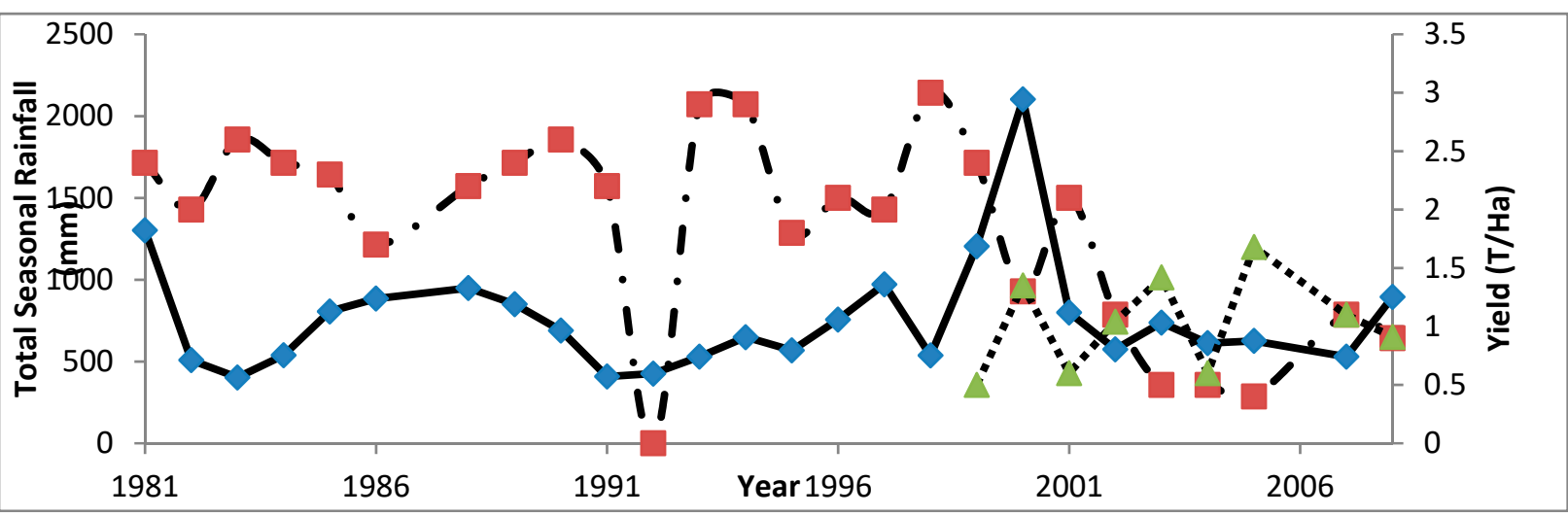

Figure 6. Relationship of total seasonal, simulated1981-2008) and observed yields 1999-2008 (dashed striped line = total seasonal rainfall; continuous line = simulated yield $(T)$, dashed with stars observed yields) The correlation $(r=0.7)$ between rainfall characteristics and maize yield shows that annual number of the rain days had strong (significant) positive correlation with maize yield; while dates of onset ( $\mathrm{r}$ $=0.003$ ) had weak correlations with maize yield (Table 8 ). This implies that variations in annual rain days and annual rainfall amounts account for most for the annual variations in maize yield. This confirms the findings by (Geerts and Raes, 2012; Mhizha et al., 2014; Raes et al., 2004; Zinyengere et al., 2014) who reported that annual rain days and annual amount had the greatest effect on maize yield. Thus, the higher the amount of rainfall spread over the number of rain days in a year, the greater the maize yields.

With the seasonal length varying from 90-139 days, the results show that the length of growing period is not very reliable to maize production but very suitable for drought tolerant crops like sorghum and finger millet. Seed companies in Zimbabwe have a range of sorghum varieties which can be grown throughout the country but particularly in areas where maize is a high-risk crop. In these areas where the higher drought tolerance of sorghum is so important it is more likely to produce a crop in years with less than average rainfall.

Table 8. ANOVA for regression of observed average yield on number of rain days

\begin{tabular}{llllll}
\hline Source & df & SS & MS & F value & Prob>F \\
\hline Regression & 1 & 0.957656 & 0.95766 & 16.42 & 0.0049 \\
Residual & 7 & 0.408231 & 0.05832 & & \\
Total & 8 & 1.36589 & & & \\
R-squared = $\mathbf{0 . 7 0 1 1}$ (adjusted = 0.6584) & & & & & \\
\hline
\end{tabular}

In rain-fed maize production, low yield experienced in marginal areas in Zimbabwe are attributed to lack of moisture, soil fertility, lack of know-how- agronomic management and lack of resources. It is clear that the typical average yields experienced in marginal areas of Zimbabwe (0.4 to $1 \mathrm{t} / \mathrm{ha}$ ) are common when few rain days and poor fertilizer application experienced despite other agrometeorological factors (Mhizha et al., 2014; Mugalavai et al., 2008; Raes et al., 2004). Number of raindays are strongly correlated $(r=0.7)$ to district maize average yield. The more the rain days the more the more the water availability in the root zone. 


\subsubsection{Maize (Crop Calendar) in Hwedza (Decision support tool)}

The decision support tool for maize production was developed for Hwedza district (Figure 7). The tool was developed based on triangulation of the survey results, analysis of 49 years' historic climatic data for Hwedza climate station and simulation results by DSSAT model. The tool is meant to help maize producers, to make decisions for maize production management based on the climate variability in Hwedza.

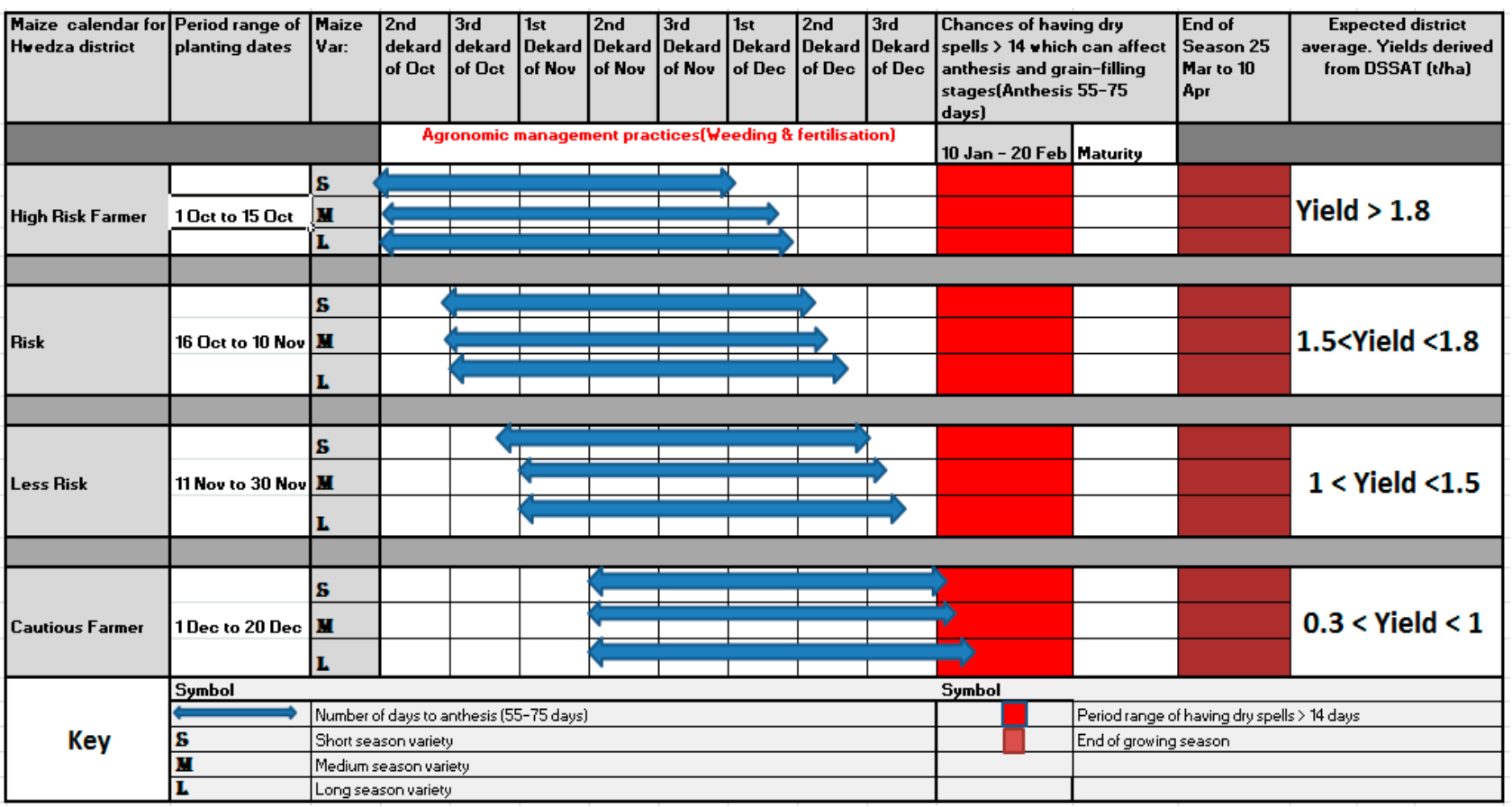

Figure 7. Maize crop calendar for Hwedza District

In applying the decision support tool, farmers, it should be noted that when they plant early the district average yields as high as $1.8 \mathrm{t}$ can be attained if the long, medium and short varieties are planted between 1 October to 10 November) with their current fertilizer application.

In general, highest maize yields in the crop calendar are obtained after averaging few success years with October plantings due to favorable heat units for hybrid maize growth (Geerts and Raes, 2012; Mhizha et al., 2014; Zinyengere et al., 2014), but these can usually only be sustained with irrigation. However, plantings in October may be feasible on vleis or when there are good early rains (over 40 $\mathrm{mm}$ ). Early planting in October in figure 3.7 has fewer chances of successes in crop establishment due to dry spells which often occurs after early plantings.

The red color represents the chances of having mid-season dry spells, which are greater than 14 days. Planting in December produce low yields and is very risky because the crop may suffer from water stress at the end of season, while pests like stalk borer and disease (maize streak virus are more prevalent to late planted maize crop.

The blue lines represent period from planting to anthesis stage. The brown strip represents the common end of season. It is clear that with the use of DSSAT model, the length and the quality of the growing period can be assessed for its suitability to rainfed production of maize varieties (Chisanga et al., 2017; Chivenge et al., 2015; Ndawayo et al., 2017; Zinyengere et al., 2015). As a result, a crop calendar that can be used to indicate whether to grow maize varieties of particular length of growth cycle was developed for Hwedza district. 
422

423

424

425

426

427

428

429

430

431

432

433

434

435

436

437

438

439

440

441

442

443

444

445

446

447

448

449

450

451

452

453

454

455

456

457

458

459

460

461

462

463

\section{Conclusions}

The maize cropping calendar (guidelines) was successfully developed as a general guide applicable to the study area.

The survey helped to find agro-meteorological challenges which are affecting maize production in Hwedza district of Zimbabwe. Results of this study indicate that rain fed maize farming in Hwedza is constrained by inadequate precipitation. The survey results showed that the start of the season was very variable generally ranging from the $1^{\text {st }}$ dekad of October to the $1^{\text {st }}$ dekad of December. The survey concludes that $56.2 \%$ of the farmers grew short season varieties, $40.2 \%$ medium season varieties and $3.6 \%$ long season varieties.

The study has established that there is high variability in rainfall characteristics (start of season, number of rain days and dry spell length) which translates into high variability in maize yield per hectare. The result also reveals that the number of rain days the strongest influence on maize yield per hectare in the study area $(r=0.7)$ while start of season has less effect on district average maize yield $(r=0.003)$.

Use of one station based climatic data for the study area does not represent the whole study area, therefore use spatial data might help to come up with cropping guidelines.

The validated DSSAT model was applied together with an optimization to select the best combination of planting criteria and maize cultivar. The study showed that maize cultivar and planting date affect maize yields considerably. The DEPTH criterion and medium season cultivar produced the highest district average yield of $0.9 \mathrm{t} / \mathrm{ha}$.

Though crop modelling approach can be used to develop cropping guidelines, this study reveals that dedicated local knowledge is necessary to calibrate and validate models.

\section{References}

A Ahmed, M., F Magda, A., H Afifi, M., 2018. Alleviation of Water Stress Effects on Maize by Mepiquat Chloride.

Alumira, J., Rusike, J., 2014. The Green Revolution in Zimbabwe e JADE The Green Revolution in Zimbabwe. Asseng, S., 2015. Uncertainties of Climate Change Impacts in Agriculture. Procedia Environ. Sci. 29, 304. https://doi.org/10.1016/j.proenv.2015.07.276

Bank, T.W., Change, C., 2018. Forests and Fire : Strengthening Prevention and Management in India.

Basir, A., Aziz, A., Khan, M.A., Khan, I., 2018. Phenology and growth traits response of maize (Zea mays L .) genotypes to semi- arid conditions 2.

CAO, H., HANAN, J.S., LIU, Y., LIU, Y., YUE, Y., ZHU, D., LU, J., SUN, J., SHI, C., GE, D., WEI, X., YAO, A., TIAN, P., BAO, T., 2012. Comparison of Crop Model Validation Methods. J. Integr. Agric. 11, 1274-1285. https://doi.org/https://doi.org/10.1016/S2095-3119(12)60124-5

Chimonyo, V.G.P., Modi, A.T., Mabhaudhi, T., 2016. Simulating yield and water use of a sorghum-cowpea intercrop using APSIM Simulating yield and water use of a sorghum - cowpea intercrop using. Agric. Water Manag. 177, 317-328. https://doi.org/10.1016/j.agwat.2016.08.021

Chisanga, C.B., Phiri, E., Chinene, V.R.N., 2017. Climate change impact on maize (Zea mays L .) yield using 
crop simulation and statistical downscaling models : A review 12, 167-187. https://doi.org/10.5897/SRE2017.6521

Chivenge, P., Mabhaudhi, T., Modi, A.T., Mafongoya, P., 2015. The potential role of neglected and underutilised crop species as future crops under water scarce conditions in Sub-Saharan Africa. Int. J. Environ. Res. Public Health 12, 5685-5711.

Conway, D., Persechino, A., Ardoin-bardin, S., Hamandawana, H., Dieulin, C., Mahe, G., 2008. Rainfall and water resources variability in Sub-Saharana Africa during the 20th century (No. Working paper number 119). Norwich, United Kingdom.

Crop, A., Society, S., Masanganise, J., Chipindu, B., Mhizha, T., Mashonjowa, E., Pleasant, M., 2012a. Model prediction of maize yield responses to climate change in north-eastern zimbabwe 20, 505-515.

Crop, A., Society, S., Mugandani, R., Wuta, M., Makarau, A., Chipindu, B., Gweru, S.R., Pleasant, M., Pleasant, M., 2012b. Re-classification of agro-ecological regions of zimbabwe in conformity with climate variability and change 20, 361-369.

Crop, S.R., 2013. Ministry of Agriculture ,Mechanisation and Irrigation Development.

Davis, J.A., Mittard, V., Saunders, R., 2016. Sampling of Commonly used Population Characteristics: Is A Normal Approximation Valid?, Value in Health. https://doi.org/10.1016/j.jval.2016.09.165

Division, S., Banda, J.P., 2003. by.

Fiwa, L., Resources, N., Raes, D., 2014. Effect of rainfall variability on the length of crop growing period over the past three decades in central Malawi Effect of rainfall variability on the length of crop growing period over the past three decades in central Malawi. https://doi.org/10.3354/cr01263

Gallagher, J., Stern, R., 2015. GENSTAT FOR WINDOWS James Gallagher and Roger Stern Updated for Version 11 by Andy Palmer and Sonya Latham.

Geerts, S., Raes, D., 2012. RELATIVE TRANSPIRATION AS A DECISION TOOL IN CROP MANAGEMENT: A.

Gracia Romero, A., Vergara, O., Thierfelder, C., Cairns, J., Kefauver, S., Araus, J., 2018. Phenotyping Conservation Agriculture Management Effects on Ground and Aerial Remote Sensing Assessments of Maize Hybrids Performance in Zimbabwe, Remote Sensing. https://doi.org/10.3390/rs10020349

Hertel, T., Lantz C. Baldos, U., 2016. Climate Change Impacts in Agriculture. https://doi.org/10.1007/978-3-31922662-0_6

Hsiao, T.C., Heng, L., Steduto, P., Rojas-lara, B., Raes, D., Fereres, E., 2009. AquaCrop-The FAO Crop Model to Simulate Yield Response to Water: III. Parameterization and Testing for Maize. https://doi.org/10.2134/agronj2008.0218s

Johnson, M., Chivandi, E., 2010. Land ownership and range resources management in Zimbabwe: A historical review.

Jones, J.W., Hoogenboom, G., Porter, C.H., Boote, K.J., Batchelor, W.D., Hunt, L.A., Wilkens, P.W., Singh, U., Gijsman, A.J., Ritchie, J.T., 2003. The DSSAT cropping system model.

Journal, T., 1983. The Journal of the University of Zimbabwe.

K. L. MACKERRON, D., 1999. Understanding Options for Agricultural Production. Edited by G. Y. Tsuji, G. Hoogenboom and P. K. Thornton. Dordrecht, The Netherlands: Kluwer Academic Publishers (1998), pp. 399, £199.00. ISBN 0-7923-4833-8., Experimental Agriculture. https://doi.org/10.1017/S001447979939311X

Keating, C., Rogers, R., Unal, R., Dryer, D., Sousa-Poza, A., Safford, R., Peterson, W., Rabadi, G., 2003. System of Systems Engineering, Engineering Management Review, IEEE. https://doi.org/10.1109/EMR.2008.4778760 
Kosgei, J.O.B.R., 2009. RAINWATER HARVESTING SYSTEMS AND THEIR INFLUENCES ON FIELD SCALE SOIL HYDRAULIC PROPERTIES, WATER FLUXES AND CROP PRODUCTION.

Kuri, F., Murwira, A., Murwira, K.S., Masocha, M., 2014. International Journal of Applied Earth Observation and Geoinformation Predicting maize yield in Zimbabwe using dry dekads derived from remotely sensed Vegetation Condition Index. Int. J. Appl. Earth Obs. Geoinf. 33, 39-46. https://doi.org/10.1016/j.jag.2014.04.021

Mabhaudhi, T., Chibarabada, T.P., Grace, V., Chimonyo, P., Modi, A.T., 2018. Modelling climate change impact: A case of bambara groundnut (Vigna subterranea ) Modelling climate change impact: A case of bambara groundnut ( Vigna subterranea ). Phys. Chem. Earth 0-1. https://doi.org/10.1016/j.pce.2018.01.003

Mapfumo, P., 2013. Review of Research and Policies for Climate Change Adaptation in the Agriculture Sector in Southern Africa. https://doi.org/10.13140/2.1.4821.9526

Matutu, V., 2014. Zimbabwe Agenda for Sustainable Socio-Economic Transformation [ZIMASSET 2013-2018] A Pipeline Dream or Reality. A Reflective Analysis of the Prospects of the Economic Blue Print, SSRN Electronic Journal. https://doi.org/10.2139/ssrn.2505008

Mendelsohn, R., 2008. The Impact of Climate Change on Agriculture in Developing Countries The Impact of Climate Change on Agriculture in Developing Countries 0459. https://doi.org/10.1080/19390450802495882

Mhizha, T., 2010. INCREASE OF YIELD STABILITY BY STAGGERING THE SOWING DATES OF DIFFERENT VARIETIES OF RAINFED MAIZE.

Mhizha, T., Geerts, S., Vanuytrecht, E., Makarau, A., Raes, D., 2014. sowing guidelines for rainfed maize in Zimbabwe 40, 233-244.

Mtambanengwe, F., Mapfumo, P., 2005. Organic Matter Management as an Underlying Cause for Soil Fertility Gradients on Smallholder Farms in Zimbabwe. Nutr. Cycl. Agroecosystems 73, 227-243. https://doi.org/10.1007/s10705-005-2652-x

Mugalavai, E.M., Kipkorir, E.C., Raes, D., Rao, M.S., 2008. Analysis of rainfall onset, cessation and length of growing season for western Kenya 148, 1123-1135. https://doi.org/10.1016/j.agrformet.2008.02.013

Mukhtar, A., 2012. Improving Soil Fertility Recommendations in Africa Using the Decision Support System for Agrotechnology Transfer (DSSAT). Edited by J. Kihara, D. Fatonji, J. W. Jones, G Hoogenboom, R. Tabo and A. Bationo. New York: Springer (2012), pp. 195, US\$165.87. ISBN 978-94-007-2959-9., Experimental Agriculture. https://doi.org/10.1017/S0014479712000592

Mupangwa, W., Maize, I., Walker, S., Africa, S., 2011. Start, end and dry spells of the growing season in semiarid southern Zimbabwe. https://doi.org/10.1016/j.jaridenv.2011.05.011

Mutowo, G., Chikodzi, D., Mutowo, G., Chikodzi, D., 2014. Remote sensing based drought monitoring in Zimbabwe. https://doi.org/10.1108/DPM-10-2013-0181

Ndawayo, B.A., Shamsudin, M.N.B., Radam, A.B., Makmom, A., Abdullah, B., 2017. Impact of climate change hange on maize yield in the maize growing rowing region of 6, 20-24.

Nyamangara, J., M. Mugwira, L., E. Mpofu, S., 2000. Soil Fertility Status in the Communal Areas of Zimbabwe in Relation to Sustainable Crop Production, Journal of Sustainable Agriculture - J SUSTAINABLE AGR. https://doi.org/10.1300/J064v16n02_04

Peytchev, A., Carley-baxter, L.R., Black, M.C., 2011. Multiple Sources of Nonobservation Error in Telephone Surveys : Coverage and Nonresponse. https://doi.org/10.1177/0049124110392547

Phillips, J., Cane, M., Rosenzweig, C., 1998. ENSO, seasonal rainfall patterns and simulated maize yield 
variability in Zimbabwe, Agricultural and Forest Meteorology. https://doi.org/10.1016/S01681923(97)00095-6

Phillips, S.J., Anderson, R.P., Schapire, R.E., 2006. Maximum entropy modeling of species geographic distributions 190, 231-259. https://doi.org/10.1016/j.ecolmodel.2005.03.026

Pickering, N., 1996. Potential Uses and Limitations of Crop Models. https://doi.org/10.2134/agronj1996.00021962008800050005x

Quantity, T.H.E.U.K., Marsh, D.B., 2017. Doctoral Thesis.

Raes, D., Sithole, A., Makarau, A., Milford, J., 2004. Evaluation of first planting dates recommended by criteria currently used in Zimbabwe. Agric. For. Meteorol. 125, 177-185. https://doi.org/10.1016/j.agrformet.2004.05.001

Scafetta, N., West, B., 2009a. Interpretations of climate-change data, Physics Today. https://doi.org/10.1063/1.3265248

Scafetta, N., West, B.J., 2009b. Is climate sensitive to solar variability ? 1-3. https://doi.org/10.1063/1.3265248

Sithole, A., Murewi, C., 2009. Climate variability and change over southern Africa: Impacts and challenges, African Journal of Ecology. https://doi.org/10.1111/j.1365-2028.2008.01045.x

The African e-Journals Project has digitized full text of articles of eleven social science and humanities journals . This item is from the digital archive maintained by Michigan State University Library . Find more at: A SCENARIO OF CHANGES IN SUBSISTENCE LAND USE AND ITS RELEVANCE TO THE TRIBAL AREAS OF ZIMBABWE, n.d.

Unganai, L.S., Kogan, F.N., 1993. Drought Monitoring and Corn Yield Estimation in Southern Africa from AVHRR Data 4257.

Vanuytrecht, E., Raes, D., Hsiao, T., Fereres, E., Heng, L., García-Vila, M., Mejías, P., 2014. AquaCrop: FAO’S crop water productivity and yield response model, Environmental Modelling and Software. https://doi.org/10.1016/j.envsoft.2014.08.005

World, T.H.E., Annual, B., 2008. Public Disclosure Authorized THE WORLD BANK ANNUAL REPORT 2008. Zinyengere, N., Crespo, O., Hachigonta, S., Tadross, M., 2015. Crop model usefulness in drylands of southern Africa : an application of DSSAT 1862. https://doi.org/10.1080/02571862.2015.1006271

Zinyengere, N., Crespo, O., Hachigonta, S., Tadross, M., 2014. Local impacts of climate change and agronomic practices on dry land crops in Southern Africa, Agriculture, Ecosystems \& Environment. https://doi.org/10.1016/j.agee.2014.07.002

Zinyengere, N., Mhizha, T., Mashonjowa, E., Chipindu, B., Geerts, S., Raes, D., 2011. Agricultural and Forest Meteorology Using seasonal climate forecasts to improve maize production decision support in Zimbabwe 151, 1792-1799. https://doi.org/10.1016/j.agrformet.2011.07.015 